\title{
JEAN-PIERRE BOULÉ, Abdellah Taïa: la mélancolie et le cri
}

\section{Emanuela Cacchioli}

\section{(2) OpenEdition \\ Journals}

\section{Édition électronique}

URL : https://journals.openedition.org/studifrancesi/44423

DOI : 10.4000/studifrancesi.44423

ISSN : 2427-5856

\section{Éditeur}

Rosenberg \& Sellier

\section{Édition imprimée}

Date de publication : 1 juin 2021

Pagination : 254-255

ISSN : 0039-2944

\section{Référence électronique}

Emanuela Cacchioli, « Jean-Pierre boulé, Abdellah Taïa: la mélancolie et le cri », Studi Francesi [En ligne], $193($ LXV | I) | 2021, mis en ligne le 01 juillet 2021, consulté le 15 octobre 2022. URL : http://

journals.openedition.org/studifrancesi/44423; DOI : https://doi.org/10.4000/studifrancesi.44423

Ce document a été généré automatiquement le 15 octobre 2022.

\section{(c) (†)}

Creative Commons - Attribution - Pas d'Utilisation Commerciale - Pas de Modification 4.0 International - CC BY-NC-ND 4.0

https://creativecommons.org/licenses/by-nc-nd/4.0/ 


\title{
JEAN-PIERRE BOULÉ, Abdellah Taïa: la mélancolie et le cri
}

\author{
Emanuela Cacchioli
}

\section{RÉFÉRENCE}

JEAN-PIERRE BOULÉ, Abdellah Taïa: la mélancolie et le cri, Lyon, Presses Universitaires de

Lyon, 2020, $368 \mathrm{pp}$.

1 Cinéaste, écrivain de nouvelles et de romans, Abdellah Taïa est né au Maroc en 1973, mais il habite en France où il a connu un succès international car ses œuvres ont été publiées en plusieurs langues. Comme il aborde des thématiques telles que les questions intimes, le sexe et l'homosexualité, il fait partie de la "génération du je», un groupe de jeunes auteurs maghrébins qui écrivent à la première personne du singulier afin de montrer leur intériorité et leur volonté de se définir en tant qu'individus.

2 Abdellah Taïa a vécu son enfance à Salé, au Maroc, dans une famille arabophone modeste et avec peu de moyens économiques. Il reçoit une formation arabe dans les écoles publiques. Quand il se rend compte que son désir est devenir réalisateur, pour être admis à l'école nationale supérieure des métiers de l'image et du son, il est obligé de se déplacer à Rabat et d'étudier le français. C'est le début d'une mission qui le conduit à maîtriser cet idiome à tel point qu'il le choisira comme langue d'écriture pour ses œuvres. En 1998, il quitte le Maroc pour Genève, où il poursuivra ses études en littérature française. L'année suivante, il s'installe à Paris où il obtient un DEA à la Sorbonne et où il gagne sa vie en tant que traducteur, plongeur et baby-sitter. En 2006 il avoue son homosexualité, bien qu'il soit conscient qu'au Maroc elle est encore considérée comme un crime. Les conséquences de sa révélation sont immédiates: dans son pays natal, le débat est très vif et sa famille ne lui manifeste aucune solidarité. Au contraire, elle ne comprend pas son engagement pour la revendication de la liberté de la société marocaine. Une séparation s'impose et ce n'est qu'en 2009 qu'Abdellah Taïa écrit une lettre ouverte à sa famille pour expliquer les raisons de son coming out. 
3 Jean-Pierre Boulé consacre un essai critique à cet écrivain marocain pour retracer le parcours biographique et littéraire d'un intellectuel particulier qui mélange des influences multiples: la culture populaire berbère de sa mère - avec ses rituels et ses histoires orales - et le cinéma égyptien qui sollicite son imaginaire. Abdellah Taïa choisit le français comme idiome d'écriture pour «confronter l'Autre dans sa propre langue» (p. 21), pour démontrer qu'il est finalement en mesure de dominer un langage qu'il a appris à l'université. Il s'agit toutefois d'un français contaminé par l'arabe et qui résonne à plusieurs voix: l'arabe classique de son père et la langue «corporelle» de sa mère. Il est également difficile de définir le genre de prédilection d'Abdellah Taïa: l'écrivain commence par des textes courts, des nouvelles, des fragments qui racontent le Maroc «des pauvres» (p. 29) et rappellent au lecteur son enfance au Maghreb; il passe ensuite aux romans basés sur son vécu intérieur où la fiction s'accompagne d'un ton poétique. «Je suis dans tout ce que j'écris» (p.31), avoue l'auteur marocain dans un entretien. Vie et œuvres se mêlent et le résultat est une "écriture de soi», une sorte d'autofiction, même si l'écrivain n'aime pas employer ce terme pour sa production littéraire. Jean-Pierre Boulé analyse les textes d'Abdellah Taïa en ordre chronologique et les approche sous le prisme de l'intertextualité intérieure de sa création (les liens se développant entre ses récits), de la paratextualité (et notamment à partir de ses interviews et de ses posts sur les réseaux sociaux qui ont contribué à sa renommée en France), mais surtout de la biotextualité car ce sont ses données biographiques qui s'inscrivent dans son écriture. Le critique a également adopté une perspective psychanalytique pour déconstruire les écrits d'Abdellah Taïa et aborder ses récits fictionnels afin de saisir la dimension constitutive de son œuvre. Le chercheur a résumé cette composante avec les deux substantifs qu'il a mis en relief dans le titre de l'essai: la mélancolie et le cri.

Le premier concept est lié aux souvenirs de son pays natal, à son enfance, à une époque lointaine qui se transforme en nostalgie grâce à son écriture poétique. Nous retrouvons cette inspiration dans les récits qui ont été publiés entre 2004 et 2007. Jean-Pierre Boulé enquête pour montrer comment un concept occidental fonctionne dans un corps arabe dont le «tissu» est constitué par une culture et une histoire différentes. Pour récupérer cet héritage, il faut accomplir un retour en arrière et revendiquer la mélancolie qui s'en dégage. Il s'agit d'une nostalgie lucide qui prend en compte la dureté de la réalité et qui laisse un espoir car, s'il est impossible de revenir à l'enfance, on peut quand même la raconter de façon différente et faire appel à l'hybridité culturelle qui mêle les mondes de la culture arabe et européenne. La lecture psychanalytique que Boulé nous propose fait appel à une autre catégorie européenne: le chercheur constate une sorte de désespoir discret qui traverse les œuvres d'Abdellah Taïa à partir de 2006. C'est une sensation de deuil qui dérive de la perte de sa mère. Cependant la mort d'un être cher n'est pas la seule raison de son malaise. Son deuil perpétuel émane également de la séparation de sa terre natale et de ses origines. Il s'agit d'une blessure profonde et douloureuse sans remède possible car à la base de sa perception, nous trouvons un «je» éclaté qui exerce sur lui une forme de possession.

5 Le concept du cri est lié à ses revendications politiques, à la nécessité d'une dénonciation des oppressions que le peuple marocain ne cesse de subir. Taïa ne se réfère pas seulement aux homosexuels, mais à tout le monde. Son «je» est également un acte militant car son écriture se propose le but de faire entendre la voix des faibles et des humbles. Il ajoute à cette catégorie celle du migrant qu'il connaît personnellement, 
surtout quand il s'installe à Paris. Sa condition en France est comparée à un «objet chosifié» (p. 244), c'est-à-dire à la perte de toute forme d'humanité. Son départ du Maroc est donc à la base des deux composantes majeures de sa production littéraire: la mélancolie et le cri politique.

6 L'étude de Boulé prend également en considération l'activité de Taïa en tant que réalisateur et scénariste du film tiré de son propre roman L'Armée du salut et en tant que photographe dans son volume d'instantanées Maroc, 1900-1960: un certain regard. La dimension filmique est un autre élément à considérer quand on aborde ses œuvres puisque l'écrivain observe la réalité sociale à travers l'écran de son regard. L'essai contient en outre une riche bibliographie concernant la production littéraire de Taïa et les articles critiques à propos de son œuvre, mais surtout il s'enrichit d'un entretien de Boulé à l'écrivain et de trois récits inédits en français. Famille, spiritualité, dimension corporelle, mélancolie, deuil, engagement et cri politique sont les thèmes abordés par un écrivain qui est considéré hors normes, mais qui a désormais connu une reconnaissance internationale. Le volume de Jean-Pierre Boulé montre l'originalité de Taïa et d'une écriture hybride qui utilise la fiction pour pousser un cri et dénoncer toute forme d'oppression. 